\title{
Using Semipermeable Membrane Devices, Bioassays, and Chemical Analysis for Evaluation of Bioavailable Polycyclic Aromatic Hydrocarbons in Water
}

\author{
Runhui Ke, Jian Li, Min Qiao, Yiping Xu, Zijian Wang \\ State Key Laboratory of Environmental Aquatic Chemistry, Research Center for Eco-Environmental Sciences, Chinese Academy of Sciences, \\ P. O. Box 2871, Beijing, 100085, China
}

Received: 23 July 2006/Accepted: 25 December 2006

\begin{abstract}
Meiliang Bay is a sublake of Taihu Lake and has been polluted by domestic and industrial effluents. As part of a comprehensive risk assessment project in this region, semipermeable membrane devices (SPMDs) were applied to evaluate the levels and potential toxic potency of polycyclic aromatic hydrocarbons (PAHs) in lakewater, in combination with chemical analysis and in vitro bioassay using H4IIE rat hepatoma cells. In addition, induction of hepatic ethoxyresorufin- $O$-deethylase (EROD) activity, in crucian carp (Carassius auratus), caged in the vicinity of SPMD sampling sites was also used as a biomarker of exposure to PAHs and related chemicals. The caged crucian carp accumulated similar PAH profile patterns $(p<0.001)$ but at lower levels compared with SPMDs on a wet-weight basis. Total concentrations of PAHs in crucian carp muscle tissues ranged from 35.6 to $69.1 \mathrm{ng} / \mathrm{g}$ after the 32-day exposure, whereas total PAHs in SPMDs ranged from 716.9 to $1007.8 \mathrm{ng} / \mathrm{g}$. Dialysates from SPMDs exposed to Meiliang Bay water caused marked EROD activity in H4IIE cells. Toxic potency of dialysates expressed as bioassay-derived 2,3,7,8-tetrachlorodibenzo- $p$-dioxin equivalents (TCDD-EQ) ranged from 3.8 to $6.2 \mathrm{pg}$ TCDD-EQ/g SPMD for 32-day exposure samples. A linear correlation of total amount of PAHs and in vitro TCDD-EQ of SPMD dialysates yielded an $R^{2}$ of 0.82. Empirical evidence suggests that aryl hydrocarbon receptor-active PAHs can account for about $42-56 \%$ of the potency observed. Significant induction of liver EROD activity was also observed in crucian carp caged alongside SPMDs and there was a good correlation between the results of EROD assays in vivo and in vitro $\left(R^{2}=0.62, p=0.02\right)$. It is, therefore, suggested that the SPMD technique in connection with chemical analysis and specific in vitro bioassays might be a valuable tool to assess the levels and effects of bioavailable hydrophobic pollutants in water.
\end{abstract}

Polycyclic aromatic hydrocarbons (PAHs) are of great concern because they are widely distributed in the environment and

Correspondence to: Zijian Wang; email: wangzj@rcees.ac.cn many of them might induce a number of adverse effects, such as immunotoxicity, genotoxicity, carcinogenicity, and reproductive toxicity (Sverdrup et al. 2002). The main source of PAHs in aquatic ecosystems is atmospheric deposition of fossil fuel combustion by-products; other important sources include industrial discharges, forest fires, decomposition of organic materials, and oil spills (Rand et al. 1995). The presence of these contaminants in the aquatic systems poses a serious threat to environmental health. Exposure assessment is a fundamental part of defining the potential for adverse effects on aquatic organisms and, ultimately, humans. Performing a comprehensive risk assessment of an aquatic system requires information about the bioavailable aqueous fraction of the contaminants. Although the bioavailability of contaminants in the environment is important for human health and other environmental quality reasons, it is often difficult to assess. Biomonitoring is an obvious means of performing assessment, but biological measurements often exhibit many limitations, such as lacking adequate precision for regulatory purposes, and are time-consuming and expensive. Therefore, new and improved methods for estimating the levels and potential toxicities of bioavailable organic contaminants are needed.

As an alternative to traditional biomonitoring methods, attention has been placed on the use of abiotic accumulators of contaminants. Semipermeable membrane devices (SPMDs) are low-density polyethylene (LDPE) tubes filled with a thin layer of lipidlike substance (triolein) and are shown to be suitable for determining concentrations of in situ bioavailable lipophilic contaminants to which aquatic organisms are exposed (Huckins et al. 1990). SPMDs have been successfully used to sample a diverse array of organic contaminants, including PAHs, chlorinated pesticides, polychlorinated biphenyls (PCBs), and polychlorinated dibenzo- $p$-dioxins and furans (PCDD/Fs) (Hofelt and Shea 1997; Gale et al. 1997; Lebo et al. 1992; Verweij et al. 2004).

The use of biomarkers might provide an early warning of potential ecosystem degradation, contaminant bioavailability, and toxicity to exposed organisms. In addition to the in vivo biomarkers, in vitro tests are increasingly used as screening tools in risk assessments because of their relatively low cost, ability to screen many samples over multiple orders of magnitude with high statistical power, ability to integrate the response of all the chemicals in the mixture, and the insight they give into 
mechanisms of toxic action. Specifically, ethoxyresorufin- $O$ deethylase (EROD) activity is one of the commonly applied biomarkers for characterizing the induction potency of various halogenated aromatic hydrocarbons (HAHs) containing PCBs, PCDD/Fs, and PAHs (Qiao et al. 2006a; Schmitz et al. 1995; Zacharewski et al. 1989). Certain HAHs bind to the aryl hydrocarbon receptor (AhR), which in turn initiates CYP1A1 gene transcription upon binding to the CYP1A1 regulatory region on DNA (Whitlock 1990). Induction of CYP1A1 is detected by fluorimetric measurement of EROD enzyme activity.

Despite the fact that SPMD characteristics and applications have been described extensively (Gale et al. 1997; Gilli et al. 2005; Lebo et al. 1992), its use as a pollutant-concentrating device for biological testing is relatively few. Chemical analysis provides only part of the knowledge necessary to evaluate the toxic potential of organic contaminants and does not take into consideration bioavailability or the interactions (synergism, antagonism) between pollutants in complex mixtures (Kočí et al. 2003). Therefore, use of selective bioanalytical tools, particularly in connection with chemical analysis, can circumvent these limitations and link contamination (cause) with biological effects and, therefore, provide unique information on ecosystem health (Bucheli and Fent 1995).

Taihu Lake, located in east China, is the country's third largest freshwater lake. The lake is an important resource that currently serves 33 million people and plays a critical role in the national economic development. Its waters are mainly used for drinking water, flood control, shipping, waste disposal, fisheries, aquaculture, and farming. The lake has been polluted by domestic and industrial effluents in recent decades. Meiliang Bay, at the northern tip of the lake, is known to have relatively constant concentrations of PAHs in surface waters and sediments (Qiao et al. 2006b; Wang et al. 2003). It is well known that the sediment-bound contaminants can be released into the water as a consequence of many chemical or microbial activities and might bioaccumulate through the food web. The evaluation of the concentrations and potential toxicological impact of contaminants in Meiliang Bay is relevant because the bay supplies one-third of the tap water of Wuxi City. We focus on PAHs in the present study because our previous research revealed that the organic extracts of Meiliang Bay sediment could induce significant EROD activity in H4IIE rat hepatoma cells and the observed response was mostly derived from PAHs (Qiao et al. 2006a).

Semipermeable membrane devices were deployed in this study to assess the capacity of SPMDs integrated with an in vitro EROD assay using H4IIE rat hepatoma cells to provide useful information about the toxic potential of waterborne PAHs. To validate the data obtained from the SPMDs and in vitro EROD assays, caged crucian carp (Carassius auratus) were deployed with SPMDs side-by-side at each site and liver EROD activity was determined. A time-course study was conducted to investigate the doseresponse relationship between the amounts of PAHs accumulated in SPMDs or fish tissues and the biological response. Our study also aimed to validate these monitoring methods for future water quality assessment of aquatic systems.

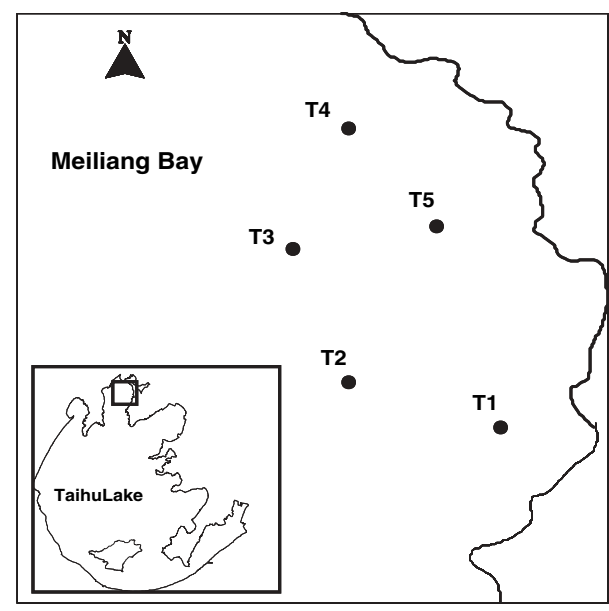

Fig. 1. Location of study sites in the Meiliagn Bay, Taihu Lake

\section{Materials and Methods}

\section{Chemicals and Reagents}

Standards of 16 US Environmental Protection Agency (EPA) priority pollutant PAHs (naphthalene [Nap], acenaphthylene [Acy], acenaphthene [Ace], fluorene [Flu], phenanthrene [Phe], anthracene [Ant], fluoranthene [Flua], pyrene [Pyr], benzo $(a)$ anthracene $[\mathrm{BaA}]$, chrysene $[\mathrm{Chr}]$, benzo $(b)$ fluoranthene $[\mathrm{BbF}]$, benzo $(k)$ fluoranthene $[\mathrm{BkF}]$, benzo $(a)$ pyrene $[\mathrm{BaP}]$, indeno(1,2,3-cd)pyrene [IcdP], dibenzo $(a, h)$ anthracene [DahA], and benzo $(g h i)$ perylene [BghiP]), phenanthrene- $d_{10}$, and hexamethylbenzene were purchased from Supelco Inc. (Bellefonte, PA). All solvents were pesticide residue grade and were purchased from Fisher Scientific (Fair Lawn, NJ). Triolein (1,2,3-tri [cis-9-octadecenoyl]-glycerol) of 95\% purity was obtained from Sigma-Aldrich Chemical Co. (St. Louis, MO). The protein standard, bovine serum albumin (BSA), was also obtained from Sigma-Aldrich as were the ethoxyresorufin and resorufin standards.

Semipermeable membrane devices were prepared in the same way as described by Huckins et al. (2000) as LDPE membranes of thickness $75-90 \mu \mathrm{m}$, and the ratio of the membrane surface area to triolein volume was $\sim 450 \mathrm{~cm}^{2} / \mathrm{mL}$. Before the deployment, they were stored in sealed acetone-rinsed stainless-steel containers at $4^{\circ} \mathrm{C}$.

Crucian carp was selected as the biomonitoring organism because it was widely distributed in the area around Taihu Lake and was suitable for the EROD assay (Wu et al. 1999). The crucian carp used in the experiment $(180 \pm 30 \mathrm{~g}, 22 \pm 2 \mathrm{~cm})$ were obtained from the hatchery of the Freshwater Fisheries Research Center, Chinese Academy of Fishery Sciences (Wuxi, China) and acclimated in the laboratory with dechlorinated tap water at least 1 week prior to use in the caging study. The water temperature was $20 \pm 2^{\circ} \mathrm{C}$ and the fish were not fed during the acclimation period.

\section{Sampling}

Fish caging experiments were carried out at five selected sites in the Meiliang Bay (Fig. 1). When transferred to cages, all of the fish were visually examined and found to be in good condition. At the field sites, the fish were placed in cages $(\sim 1 \mathrm{~m} \times 1 \mathrm{~m} \times 1 \mathrm{~m})$, which were completely submerged in a column of water ( $2 \mathrm{~m}$ depth) and fixed on a stake at the sampling sites in Meiliang Bay. At each study site, up to 25 fish in total were held in 1 cage together with 3 SPMDs for 32 days 
(except for site T1 with 15 SPMDs), during which time the fish were able to gain access to both the water column and lakebed. No attempt was made to feed the fish during the exposure period; therefore, the caged fish relied upon naturally available food items.

The water temperature at the sites varied between $19^{\circ} \mathrm{C}$ and $22^{\circ} \mathrm{C}$ during the experiment. It was hard to choose an appropriate reference site, so the crucian carp kept in the laboratory were regarded as the control fish. This solution was previously suggested by Pacheco and Santos (1999), who stated that it is the situation most similar to the uncontaminated reference site. Field SPMD blanks, which accompanied the field samplers to the sampling sites, were removed during the deployment interval and then replaced in their containers and returned to the laboratory. These field blanks were used to determine any potential airborne contamination.

Three replicate SPMDs and five fish were sampled at site $\mathrm{T} 1$ at days $2,4,8,16$, and 32 of the exposure. For another four sites, replicate SPMD and fish samples were collected only after 32 days. The fish were dissected immediately after their collection. The liver was removed, rinsed with $0.15 \mathrm{~mol} / \mathrm{L} \mathrm{KCl}$, and placed in vials, which, in turn, were placed into liquid nitrogen. Liver samples were stored in liquid nitrogen during transport to the laboratory, where they were stored at $-80^{\circ} \mathrm{C}$. The fish bodies were transported to the laboratory, where muscle tissues were isolated and stored at $-20^{\circ} \mathrm{C}$ until analysis. After retrieval, surficial material was removed from SPMDs directly using ambient water from the site and then stored in sealed glass jars and transported to the laboratory, where they were stored at $4^{\circ} \mathrm{C}$ awaiting analysis.

\section{Sample Pretreatment}

Semipermeable membrane devices were cleaned in the laboratory by scrubbing in distilled water, dipping in hexane followed by $1 \mathrm{M} \mathrm{HCl}$, and then rinsing briefly with acetone and isopropanol. Each SPMD was dialyzed twice for 24 -h period in separate $200-\mathrm{mL}$ volume of hexane at $18^{\circ} \mathrm{C}$. The extracts of dialyzate were treated with copper wool to remove sulfur and preconcentrated to $2 \mathrm{~mL}$ in a rotary evaporator (Büchi Vac V-800, Switzerland). The extracts were split into two portions: One portion was evaporated to dryness with a stream of pure $\mathrm{N}_{2}$ and redissolved in dimethyl sulfoxide (DMSO) for bioassay; another portion was subjected to a further cleanup procedure and chemical analysis.

From each fish, about $12 \mathrm{~g}$ of wet muscle tissue (fillet) was dissected, homogenized, and dried with preextracted sodium sulfate. Each sample was spiked with surrogate standard (phenanthrene- $d_{10}$ ). The samples were extracted with $200 \mathrm{~mL}$ hexane/acetone (50:50, v/v) in a Soxhlet apparatus. The extracts were concentrated to $1 \mathrm{~mL}$ and solvent-exchanged to hexane.

All of the aforementioned extracts for chemical analysis were subjected to column chromatography (10 mm inner diameter) using 8-g 1:2 alumina/silica for cleanup and fractionation. The column was eluted with $15 \mathrm{~mL}$ hexane and the eluate was discarded. The second fraction containing PAHs was eluted with $70 \mathrm{~mL}$ dichloromethane/ hexane $(30: 70, v / v)$. The extracts containing PAHs were concentrated to $0.2 \mathrm{~mL}$ and an appropriate amount of internal standard (hexamethylbenzene) was added prior to instrumental analysis.

\section{Instrumental Analysis}

The PAHs were analyzed using an Agilent 6890/5973 gas chromatography-mass spectrometer (GC-MS) equipped with a DB-5 MS silica-fused capillary column $(60 \mathrm{~m} \times 0.25 \mathrm{~mm}$ inner diameter with $0.25 \mu \mathrm{m}$ film thickness). Detection was performed using the selectedion mode, and the details of instrument conditions were reported earlier (Qiao et al. 2006b).
Quantitation was performed using the internal calibration method based on the five-point calibration curve for individual components. The concentration of each of the $16 \mathrm{PAHs}$ was determined by an individual calibration database set up from the certified standards.

\section{In Vivo Bioassay}

The liver tissue $(\sim 0.1 \mathrm{~g})$ was homogenized in a glass homogenizer with $900 \mu \mathrm{L}$ ice-cold phosphate buffer solution (PBS, $\mathrm{pH}=7.4$ ) with $100 \mu \mathrm{L}$ of $10 \mathrm{mM}$ phenylmethylsulfonyfluoride (PMSF, a proteases inhibitor), and then the homogenates were centrifuged at $10,000 \mathrm{~g}$ at $4^{\circ} \mathrm{C}$ for $20 \mathrm{~min}$ in a centrifuge (Sigma, Germany). The supernatants were used for EROD and protein content determination. Liver EROD activity was measured as described by Ma et al. (2005). The cytosolic protein concentrations were determined according to Bradford et al. (1976) by using BSA as standard. In vivo EROD activity was expressed as picomoles per minute per milligram of protein.

\section{In Vitro Bioassay}

H4IIE rat hepatoma cells lines were cultured in Dulbecco's modified Eagle medium (DMEM; Gibco, Germany) supplemented with 10\% (v/ v) fetal bovine serum, $1 \%$ o (v/v) penicillin/streptomycin solution and incubated at $80 \%$ humidity and $5 \% \mathrm{CO}_{2}$ at $37^{\circ} \mathrm{C}$. The routine maintenance of cells was as described elsewhere (Qiao et al. 2006a). Cells were seeded into the 96 -well culture plates and stored at $37^{\circ} \mathrm{C}$ under $5 \% \mathrm{CO}_{2}$ in an incubator (Sanyo, Japan). After $24 \mathrm{~h}$, when a monolayer was formed consisting of $70-80 \%$ cells cover, the original culture medium was removed and replaced by a culture medium containing $2,3,7,8$ tetrachlorodibenzo- $p$-dioxin (TCDD) standard solutions or the test solutions. The standard solutions were prepared by serial dilution of TCDD stock solution that could yield a full dose-response curve of EROD induction. They were included on each plate as positive controls and for calibration purposes. SPMD samples dissolved in DMSO were added directly to the medium. Six concentration levels of test solutions were prepared by twofold dilution of each SPMD dialysate for the test. In each well, the final concentration of DMSO was about $0.5 \%$. A $0.5 \%$ DMSO solution was also used as the solvent control to eliminate artifactual effects due to DMSO. Each test solution was assayed in triplicate, and three solvent controls and three blanks were assayed simultaneously on each 96-well plate. The edges of the 96-well culture plates were wrapped with parafilm and were incubated for $72 \mathrm{~h}$ at $37^{\circ} \mathrm{C}$.

After incubation, EROD enzyme activity was analyzed following the methods of Qiao et al. (2006a). Protein concentrations were determined as described by Bradford et al. (1976). Resorufin standard curve was analyzed at the same time to convert fluorescent units to picomoles of resorufin. The bioassay-derived 2,3,7,8-tetrachlorodibenzo- $p$-dioxin equivalents (TCDD-EQ) were determined according to Hanberg et al. (1991) by comparing the induction of EROD activity caused by environmental sample extracts with that caused by authentic TCDD standards. The average deviation between duplicate measurements was $\pm 30 \%$.

\section{Data Processing}

All statistical tests were performed with the use of SPSS for Windows Version 10.0 software (SPSS Inc., USA). Differences in EROD activities between sampling sites were analyzed using a two-way analysis of variance (ANOVA). The TCDD-equivalents (TCDD-EQs) were normalized to the mass of the entire SPMD (pg TCDD-EQ/g SPMD) because compounds concentrated in the triolein as well as 
Table 1. Mean concentrations of PAHs (ng/g wet weight) and corresponding TCDD-EQs (pg TCDD-EQ/g SPMD) in SPMDs $(n=3)$ deployed at five sites in Meiliang Bay water during a 32-day exposure period

\begin{tabular}{|c|c|c|c|c|c|c|c|c|c|}
\hline & \multicolumn{5}{|c|}{ T1 (kinetic study) } & \multirow{2}{*}{$\begin{array}{l}\text { T2 } \\
32 \text { days }\end{array}$} & \multirow{2}{*}{$\begin{array}{l}\text { T3 } \\
32 \text { days }\end{array}$} & \multirow{2}{*}{$\begin{array}{l}\text { T4 } \\
32 \text { days }\end{array}$} & \multirow{2}{*}{$\begin{array}{l}\text { T5 } \\
32 \text { days }\end{array}$} \\
\hline & 2 days & 4 days & 8 days & 16 days & 32 days & & & & \\
\hline Naphthalene & 31.1 & 57.8 & 53.7 & 112.4 & 101.3 & 240.2 & 195.3 & 189.8 & 142.1 \\
\hline Acenaphthylene & $-^{\mathrm{a}}$ & 7.4 & 8.4 & 17.5 & 17.8 & 20.5 & 26.2 & 25.3 & 20.1 \\
\hline Acenaphthene & 0.4 & 4.2 & 8.1 & 19.5 & 22 & 21.8 & 22.1 & 20.3 & 18.1 \\
\hline Fluorene & 13.6 & 24.5 & 25.7 & 28.5 & 28.7 & 39.9 & 33.9 & 30.6 & 29.3 \\
\hline Phenanthrene & 12.2 & 23.4 & 48.2 & 62.7 & 68.3 & 74.4 & 66 & 63.4 & 78.2 \\
\hline Anthracene & 1.7 & 4.6 & 5.8 & 10.3 & 20.2 & 19.8 & 17.9 & 18.7 & 17 \\
\hline Fluoranthene & 22.9 & 88.1 & 143.6 & 150.7 & 181.3 & 235.2 & 209.5 & 184.6 & 209.3 \\
\hline Pyrene & - & 89.2 & 113.4 & 130.1 & 141.7 & 166.2 & 164.5 & 211.6 & 179.1 \\
\hline Benz(a)anthracene & 0.1 & 4.6 & 8.1 & 16 & 21.9 & 24.5 & 24.9 & 38.2 & 27.3 \\
\hline Chrysene & 2.6 & 5.8 & 9.8 & 13 & 12.6 & 19.1 & 17.2 & 18.9 & 15.8 \\
\hline $\operatorname{Benzo}(b)$ fluoranthene & 4.7 & 11.5 & 19.2 & 27.8 & 36.7 & 73.3 & 58.3 & 87.1 & 65 \\
\hline $\operatorname{Benzo}(k)$ fluoranthene & 3.2 & 5.1 & 6 & 9 & 11.8 & 13.1 & 11.8 & 19.2 & 13 \\
\hline Benzo(a)pyrene & 2.9 & 5 & 7.2 & 7.9 & 13.5 & 11.5 & 10.2 & 14 & 11.6 \\
\hline $\operatorname{Dibenzo}(a, h)$ anthracene & 3.7 & 6.4 & 9 & 11.9 & 16.2 & 16 & 11.8 & 30.3 & 14.4 \\
\hline Indeno(1,2,3-cd)pyrene & 2.6 & 3.9 & 4.2 & 4.6 & 7.3 & 6.8 & 7.8 & 6.4 & 4.6 \\
\hline Benzo(g,h,i)perylene & 4.3 & 4.8 & 5.4 & 8.1 & 15.5 & 25.5 & 17.6 & 23.3 & 21.9 \\
\hline$\sum \mathrm{PAHs}$ & 106.2 & 346.5 & 475.8 & 630 & 716.9 & 1007.8 & 895.1 & 981.7 & 866.7 \\
\hline $\mathrm{TCDD}^{-E^{\mathrm{b}}}{ }^{\mathrm{b}}$ & - & 0.5 & 1.1 & 2.2 & 4.7 & 4.6 & 3.8 & 6.2 & 5.2 \\
\hline $\mathrm{TEQ}_{\mathrm{cal}}^{\mathrm{c}}$ & 0.5 & 0.8 & 1.1 & 1.5 & 2 & 2.3 & 2 & 3.5 & 2.2 \\
\hline
\end{tabular}

${ }^{a}$ Values are under detection limits.

${ }^{\mathrm{b}}$ Bioassay-derived TCDD-EQ.

${ }^{c}$ Chemically derived TCDD-EQ.

those bound to the LDPE membrane are collected by dialysis. We did not use lipid-normalized SPMD or fish concentration data, because it is inappropriate to do so when either SPMDs or fish are in the linear or curvilinear phases of chemical uptake during the exposure (Huckins et al.1996).

\section{Results}

The individual and total concentrations of 16 PAHs measured in SPMDs and crucian carp muscle tissues from five sites in Meiliang Bay are reported in Table 1 and Table 2, respectively. Caged fish accumulated similar PAH composition patterns $(p<0.001)$ but lower concentrations compared with SPMDs at all sites after 32 days exposure. On a wet-weight basis, the PAH concentrations in SPMDs were about an order of magnitude higher than those in crucian carp tissues (Table 1). This was not surprising because it had been shown in a number of field studies (Gale et al. 1997; Hofelt and Shea 1997; Moring and Rose 1997) that SPMDs accumulate higher concentrations of hydrophobic pollutants than do aquatic organism when deployed alongside.

Marked EROD induction was observed for all SPMDs dialysates from the 32-day kinetic study at site T1. Dialysates from SPMDs with longer exposures generally induced stronger activity, indicating greater potency. Bioassay-derived TCDD-EQs increased markedly with SPMD exposure duration (Fig. 2A), from 0.5 pg (day 4) to 4.7 pg (day 32) TCDDEQs/g SPMD (the bioassay-derived TCDD-EQ of the SPMD dialysate from the control and 2-day exposure was under the detection limit of H4IIE assay). The total amount of PAHs accumulated in SPMDs also increased with exposure duration, rising from 106.2 (day 2) to 716.9 (day 32) ng/g (Ta- ble 1). The EROD activity in SPMDs dialysates from the 32day exposure collected from five sites ranged from 3.8 to 6.2 pg TCDD-EQs/g SPMD and the corresponding total PAH concentrations in these SPMDs ranged from 716.9 to 1007.8 ng/g, respectively (Fig. 2B). A correlation between TCDDEQs of SPMD dialysates and total PAHs produced an $R^{2}$ of $0.82(n=8, p=0.002)$. Because several PAHs, including $\mathrm{BkF}, \mathrm{BaP}, \mathrm{BbF}, \mathrm{Chr}, \mathrm{BaA}, \mathrm{IcdP}$, and DahA, have been shown to elicit a dioxinlike response or induce EROD activity in both in vivo and in vitro bioassays (Machala et al. 1996; Van der Weiden et al. 1994), we repeated the analysis using the total concentrations of these seven AhR-active PAHs. The results of this approach showed an improved correlation $\left(R^{2}=0.90, n=8, p<0.001\right)$. This improvement appeared to be due to their higher affinity for the Ah receptor than PAHs of lower molecular weight; these seven AhR-active PAHs would account for the majority of the EROD induction activity in extracts containing complex mixtures of PAHs (Piskorska-Pliszczynska et al. 1986).

No mortality was observed during the field-study experiment of caged crucian carp. In the time-course study at site T1, the total amounts of PAHs accumulated in caged fish muscle tissues initially increased with exposure time from 14.3 (day 0) to 54.4 (day 16) ng/g wet weight, followed by a slight decrease from 54.4 to 49.5 (day 32) ng/g wet weight. (Table 2). The total PAH concentrations of the caged fish samples collected from five sites on day 32 of deployment range from 35.6 to $69.1 \mathrm{ng} / \mathrm{g}$ wet wt. (Table 2). A significant liver EROD activity increase was observed after 16 days of caging compared with control fish $(p<0.01)$ and there was a consistent trend for elevation in EROD levels from day 8 to day 32 from the 32-day kinetic study at site T1 (Table 2). EROD activity was significantly higher $(p<0.01)$ in fish caged in all five sites compared with 
Table 2. Mean concentrations of PAHs (ng/g wet weight) and liver EROD acitivity ( $\mathrm{pmol} / \mathrm{min} / \mathrm{mg}$ protein) in crucian carp $(n=5)$ deployed at five sites in Meiliang Bay water during the 32-day exposure period

\begin{tabular}{|c|c|c|c|c|c|c|c|c|c|}
\hline & \multicolumn{5}{|c|}{ T1 (kinetic study) } & \multirow{2}{*}{$\begin{array}{l}\text { T2 } \\
32 \text { days }\end{array}$} & \multirow{2}{*}{$\begin{array}{l}\text { T3 } \\
32 \text { days }\end{array}$} & \multirow{2}{*}{$\begin{array}{l}\text { T4 } \\
32 \text { days }\end{array}$} & \multirow{2}{*}{$\begin{array}{l}\text { T5 } \\
32 \text { days }\end{array}$} \\
\hline & Control & 4 days & 8 days & 16 days & 32 days & & & & \\
\hline Naphthalene & 4.2 & 11.6 & 13.7 & 17.0 & 10.6 & 9.1 & 7.2 & 10.2 & 5.5 \\
\hline Acenaphthylene & 0.7 & 1.4 & 1.8 & 2.1 & 2.1 & 1.0 & 1.2 & 1.9 & 1.2 \\
\hline Acenaphthene & 0.5 & 1.3 & 1.4 & 1.2 & 1.0 & 0.9 & 0.9 & 1.8 & 0.9 \\
\hline Fluorene & 0.7 & 2.7 & 2.7 & 2.0 & 1.8 & 2.6 & 0.9 & 2.9 & 1.8 \\
\hline Phenanthrene & 3.5 & 9.2 & 9.0 & 10.0 & 7.8 & 4.8 & 5.5 & 12.0 & 4.5 \\
\hline Anthracene & 1.1 & 1.2 & 1.8 & 2.0 & 1.9 & 1.7 & 1.2 & 2.5 & 0.7 \\
\hline Fluoranthene & 2.1 & 6.4 & 4.9 & 9.1 & 9.0 & 8.9 & 8.7 & 14.0 & 9.2 \\
\hline Pyrene & 0.6 & 1.8 & 2.1 & 4.7 & 5.8 & 5.8 & 6.8 & 10.6 & 5.9 \\
\hline $\operatorname{Benz}(a)$ anthracene & 0.3 & 0.7 & 0.9 & 1.1 & 1.5 & 1.4 & 1.3 & 2.0 & 1.0 \\
\hline Chrysene & 0.3 & 0.8 & 1.0 & 1.0 & 1.2 & 1.6 & 1.2 & 1.9 & 0.9 \\
\hline $\operatorname{Benzo}(b)$ fluoranthene & 0.3 & 0.7 & 0.8 & 1.0 & 1.8 & 1.7 & 1.4 & 2.2 & 1.0 \\
\hline $\operatorname{Benzo}(k)$ fluoranthene & $-^{\mathrm{a}}$ & 0.3 & 0.4 & 0.6 & 0.9 & 0.7 & 0.5 & 0.9 & 0.4 \\
\hline $\operatorname{Benzo}(a)$ pyrene & - & 0.3 & 0.4 & 0.5 & 0.7 & 0.7 & 0.7 & 1.2 & 0.5 \\
\hline $\operatorname{Dibenzo}(a, h)$ anthracene & - & 0.5 & 0.6 & 1.0 & 1.3 & 1.1 & 0.9 & 1.6 & 0.7 \\
\hline Indeno(1,2,3-cd)pyrene & - & 0.1 & 0.4 & 0.6 & 0.8 & 0.7 & 0.7 & 1.0 & 0.6 \\
\hline $\operatorname{Benzo}(g, h, i)$ perylene & - & 0.3 & 0.5 & 0.6 & 1.3 & 1.2 & 1.5 & 2.4 & 1.0 \\
\hline$\sum \mathrm{PAHs}$ & 14.3 & 39.2 & 42.5 & 54.4 & 49.5 & 44.0 & 40.6 & 69.1 & 35.6 \\
\hline EROD activity & $20.7 \pm 3.0$ & $24.3 \pm 4.0$ & $7.9 \pm 3.0$ & $60.1 \pm 8.5^{\mathrm{b}}$ & $162.7 \pm 30.8^{\mathrm{b}}$ & $85.6 \pm 23.4^{\mathrm{b}}$ & $117.0 \pm 15.4^{\mathrm{b}}$ & $100.9 \pm 17.0^{\mathrm{b}}$ & $94.3 \pm 30.1^{\mathrm{b}}$ \\
\hline
\end{tabular}

${ }^{a}$ Values are under detection limits.

${ }^{\mathrm{b}}$ Significant different from control and exposure groups, $p<0.01$. Values are expressed as mean \pm standard deviation.
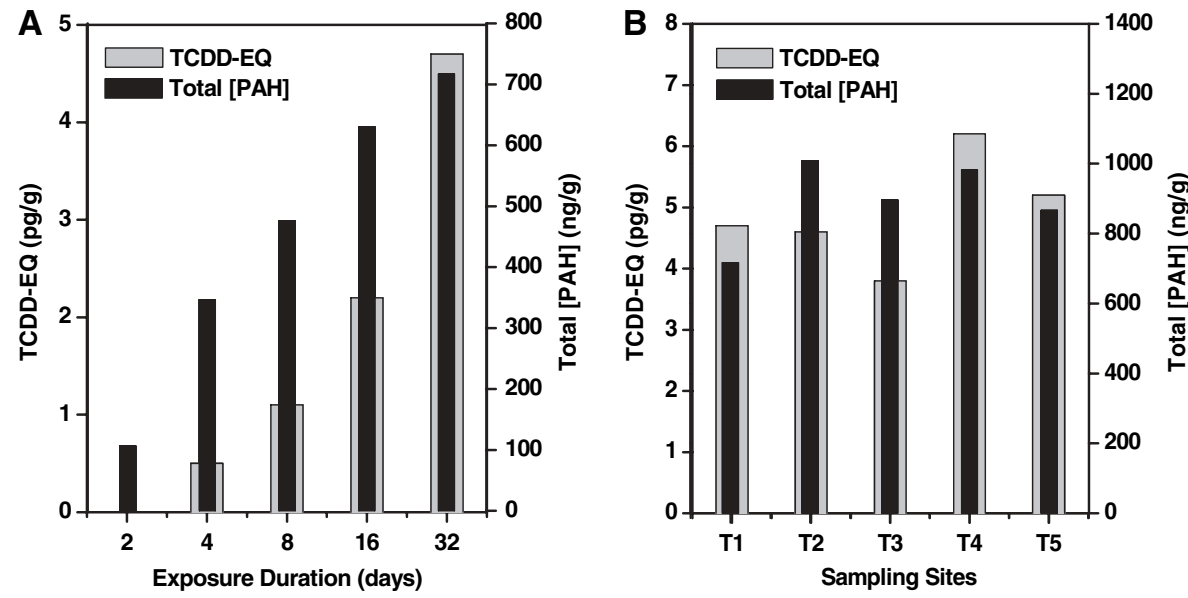

Fig. 2. Effect of duration of exposure of SPMDs to Meiliang Bay water on total PAHs and bioassay-derived TCDD-EQs associated with dialysates the control fish after 32 days of caging (Table 2). A good correlation was observed between the hepatic EROD activity in crucian carp and TCDD-EQs of SPMD dialysates based on the H4IIE cells in vitro bioassay $\left(R^{2}=0.62, n=8, p=0.02\right)$ (Fig. 3A). However, fish from the site with the highest total PAH concentrations (site T4) did not have the highest mean EROD activity and no significant correlation was observed $\left(R^{2}=0.19, n=9\right)$ in the correlation between total PAHs in caged crucian carp muscle tissues and induced EROD activity in liver. We repeated the analysis using the total concentrations of seven AhR-active PAHs, in the same way as described earlier; a significant improved correlation $\left(R^{2}=0.53, n=9\right.$, $p=0.02$ ) was obtained (Fig. 3B).

\section{Discussion}

Chemical analysis provides only part of the knowledge necessary to evaluate the toxic potential of organic contaminants to aquatic organisms and humans. They do not take into consideration the synergistic and antagonistic effects of pollutants in complex mixtures, nor do they reflect the actual bioavailability of the pollutants. Moreover, it is important to evaluate the final effect of these bioavailable contaminants to the environment, not only a chemical composition of such a sample (Kočí et al. 2003). The use of selective bioanalytical tools, particularly in connection with chemical analysis, can circumvent these limitations. 

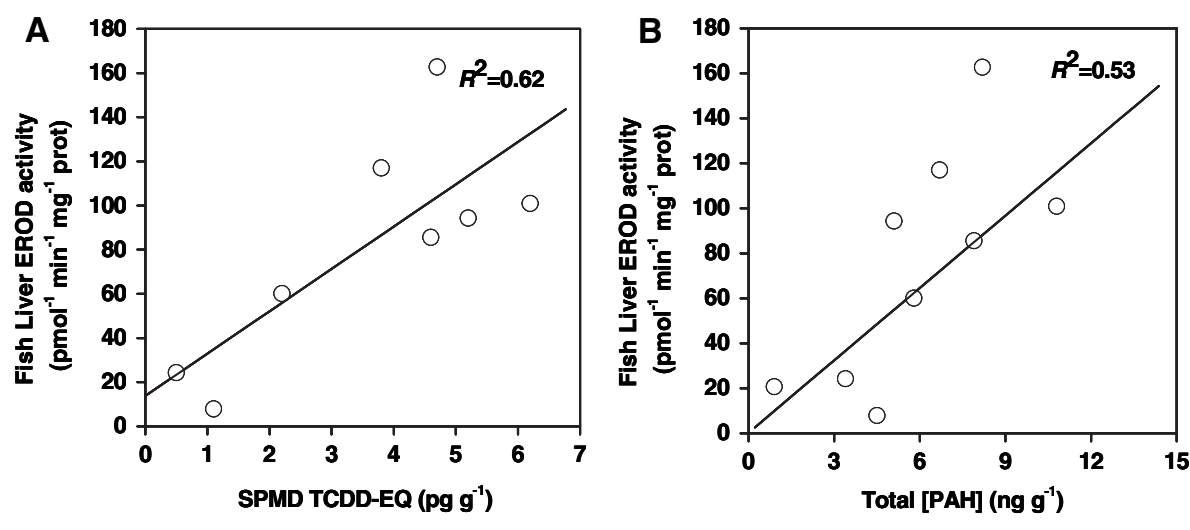

Fig. 3. A Relationship between bioassay-derived toxic equivalents of dialysates from SPMDs and induced liver EROD activities of crucian carp both exposed to Meiliang Bay water. B Relationship between the total concentrations of seven AhR-active PAHs in muscle tissues and induced liver EROD activities of crucian carp exposed to Meiliang Bay water

\section{In Vitro Assay and Chemical Data}

Use of in vitro assays of EROD induction for assessing the biological potency of environmental samples has been described (Kennedy et al. 1993; Tillit et al. 1991) and the correlation between in vitro EROD induction and adverse biological effects have indicated that such assays can be used to evaluate and compare the potential toxicity of environmental samples. H4IIE rat hepatoma cells were selected for this study because they have low basal CYP1A1-dependent activity but are highly inducible by AhR-active compounds, allowing for very sensitive assays. H4IIE rat hepatoma cells have inducible EROD activity and have been successfully used for in vitro bioassays (Tillitt et al. 1991; Wu et al. 1996). The detection limit for our in vitro EROD induction by TCDD was about $19 \mathrm{fg}$ TCDD/well. This compares favorably with sensitivities of similar bioassays reported in the literature. The reported detection limit for EROD induction in H4IIE cells was $40 \mathrm{fg}$ TCDD/well (Li et al. 2002). Sanderson et al. (1996) reported detection limits for EROD induction in H4IIE cells was $193 \mathrm{fg}$ TCDD/well.

Because many PAHs are known inducers of EROD activity (Piskorska-Pliszczynska et al. 1986; Willett et al. 1997) and our previous study has identified that observed AhR effect of sediment in this area was mostly derived from PAHs (Qiao et al. 2006a), it was thought that PAHs might also be major contributors to the bioassay-derived potency of dialysates from SPMDs exposed to Meiliang Bay water. The good correlation between in vitro EROD activities and total PAHs for SPMD dialysates indicates the ability of these in vitro assays to derive similar conclusions concerning the state of contamination at these sites compared to those stemming from the PAH data. However, it does not imply that PAHs or PAHs alone cause toxicity in this system. To test the hypothesis that AhR-active PAHs could account for the observed potency of the SPMD dialysates, the toxic equivalency factors for the induction potency of seven AhR-active PAHs relative to TCDD were used to estimate toxic equivalent (TEQ) contributed by PAHs as described by Qiao et al. (2006a). It is found that chemically

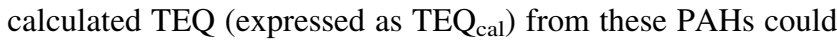
only account for $\sim 42-56 \%$ of the bioassay-derived TCDDEQs for the dialysates of 32-day exposed SPMDs (Table 1). Thus, it appears likely that there were other AhR-active compounds in the dialysates that we did not identify, such as PCDD/Fs and PCBs. Also, it has been reported that chemically derived TEQ for some mixtures were lower than bioassayderived TCDD-EQs for the same sample (Kennedy et al. 1996; Schmitz et al. 1996) which might be indicative of synergistic interaction of the contaminants and/or the presence of active compounds that are not identified by chemical analysis. These results indicated that PAHs was one of the important causes for inducing AhR effects in the water of Meiliang Bay.

\section{In Vivo Assay and Chemical Data}

Dialysates from SPMDs exposed to Meiliang Bay water for 32 days accumulated an average of about $4.9 \mathrm{pg}$ TCDD-EQs/g SPMD. This suggests that aquatic organisms in Meiliang Bay might have been exposed to an equivalent level of lipophilic AhR-active contaminants over the same period of time, because SPMDs sample only freely dissolved or bioavailable organic pollutants. Significant induced EROD activity was observed in the liver of crucian carp exposed for 32 days at all 5 sites validated the results of an in vitro bioassay with SPMD dialysates. This suggests that bioavailable lipophilic contaminants in Meiliang Bay could elicit biological response in resident aquatic organisms. Moreover, the good correlation between the results of EROD bioassay in vivo and in vitro reflected that these two methods can complement each other and be useful for monitoring AhR-active compounds in the environment. However, in vivo hepatic EROD activity measured in caged crucian carp did not correlated well with the total PAHs in tissues. This is most likely due to low-molecular PAHs that have no, or very weak, AhR-active effect (Bosveld et al. 2002; Willett et al. 1997), although they often account for considerable portions of the total PAHs. The improved resulting correlation obtained using the concentrations of seven AhR-active PAHs confirmed this point. The reason for the relatively poor correlation of the total accumulated PAHs and corresponding biological response (induced EROD activity) for caged crucian carp, compared with SPMDs, is likely due to the complex active biological processes. Tissue concentrations are dependent on some complex interplay of exposure scenario, organism behavior, physiology, and passive equilibrium partition processes (Huckins et al. 2004). Verweij et al. (2004) have suggested that PAH parent compound bioaccumulation in fish is not a reliable indicator of exposure due to biotransformation and it is more appropriate to screen biliary PAH metabolite levels. In addition, several studies have 
revealed that fish exposed to high and chronic levels of contamination might become enzymatically adapted to in situ contaminants (Elskus et al. 1999) and EROD activity might be influenced by biological characteristics of individual fish (Cavanagh et al. 2000) or with habitat variables such as temperature (Jimenez and Burtis 1989). As a measure of water quality, cytochrome $\mathrm{P} 450$ induction provides an integrated response to conditions in the aqueous environment. However, interpreting in vivo EROD assay data in terms of the effects of contaminants on the health of specimens is not straightforward. The accumulation and biotransformation of contaminants by aquatic biota are complicated functions of physical, chemical, and biological processes that confound the interpretation of results.

\section{Validity of the Results}

The SPMDs proved to be highly compatible with the in vitro bioassay method. They provided a simple time-integrated passive sample of bioavailable lipophilic contaminants from water. The way that SPMDs accumulate contaminants is analogous to aquatic organisms, which take up contaminants mostly through biomembranes such as fish gills (Huckins et al. 1990). Dialysis of contaminants from SPMDs was simple and efficient compared to extraction from tissues of exposed organisms. In this study, the controls (derived from processed unexposed SPMDs) were nontoxic in the in vitro EROD assay, indicating that SPMD-derived contaminants at these concentrations were innocuous to these biologic systems and SPMDs are therefore appropriate concentrators for use with this assay. SPMDs in connection with an in vitro bioassay could overcome the uncertainties in field organism exposure studies. Moreover, the application of SPMDs is ethically superior to using biomonitoring organisms, as no test animals have to be killed.

\section{Conclusion}

The PAH profile patterns in SPMDs and simultaneous exposed crucian carp were similar after 32 days exposure. The good correlation between the results of EROD bioassay in vivo and in vitro indicated that these two methods can be complementary and useful for monitoring AhR-active compounds in the environment. The current results showed that SPMDs combined with toxicity assays could overcome the uncertainties of using aquatic biomonitoring organisms. Application of toxicological tests for SPMD evaluation is highly recommended. It can distinguish different contamination levels of sampling sites and provide information about the action of monitored pollutants in the environment. Our method combined biologically meaningful measures of exposure effects with instrumental analysis of the mixture of compounds sorbed by SPMDs and the specific bioassay proved to be successful. Although further investigations are required, the marriage of SPMDs, chemical analysis, and compatible bioassays appears to be a useful screening approach for determining the potential consequences of exposure to bioconcentratable contaminants in the water ecosystem.
Acknowledgments. We gratefully acknowledge the support of the National Basic Research Program of China (2003CB415005), the National Natural Science Foundation of China (50538090), and the Chinese Academy of Sciences (KZCX3-SW-431) for conducting this research.

\section{References}

Bosveld ATC, de Bie PAF, van den Brink NW, Jongepier H, Klomp AV (2002) In vitro EROD induction equivalency factors for the 10 PAHs generally monitored in risk assessment studies in The Netherlands. Chemosphere 49:75-83

Braford MM (1976) A rapid and sensitive method for the quantification of microgram quantities of protein utilizing the principle of protein-dye binding. Anal Biochem 72:248-254

Bucheli TD, Fent K (1995) Induction of cytochrome P450 as a biomarker for environmental contamination in aquatic ecosystem. Crit Rev Environ Sci Technol 25:201-268

Cavanagh JE, Burns KA, Brunskills GJ, Ryan DAJ, Ahokas JT (2000) Induction of hepatic cytochrome P-4501A in pikey bream (Acanthopagrus berda) collected from agricultural and urban catchments in far north Queensland. Marine Pollut Bull 41:377384

Elskus AA, Monosson E, McElroy AE, Stegman JJ, Woltering DS (1999) Altered CYP1A expression in Fundulus heteroclitus adults and larvae: a sign of pollutant resistance? Aquat Toxicol 45:99113

Gale RW, Huckins JN, Petty JD, Peterman PH, Williams LL, Morse D, Schwartz TR, Tillitt DE (1997) Comparison of the uptake of Dioxin-like compounds by caged channel catfish and semipermeable membrane devices in the Saginaw River, Michigan. Environ Sci Technol 31:178-187

Gilli G, Schilirò T, Pignata C, Traversi D, Carraro E, Baiocchi C, Aigotti R, Giacosa D, Fea E (2005) Application of semipermeable membrane device for assessing toxicity in drinking water. Chemosphere 61:1691-1699

Hanberg A, Strahlberg M, Georgellis A, de Wit C, Ahlborg UG (1991) Swedish dioxin survey: evaluation of the H4IIE bioassay for screening environmental samples for dioxin-like enzyme induction. Pharmacol Toxicol 69:442-449

Hofelt CS, Shea D (1997) Accumulation of organochlorine pesticides and PCBs by semipermeable membrane devices and $M y$ tilus edulis in New Bedford Harbor. Environ Sci Technol 31:154-159

Huckins JN, Petty JD, Lebo JA, Orazio CE, Prest HF, Tillitt DE, Ellis GE, Johnson BT, Manuweera GK (1996) Semipermeable membrane devices (SPMDs) for the concentration and assessment of bioavailable organic contaminants in aquatic environments. In: Ostrander GK (ed) Techniques in Aquatic Toxicology. CRC Press, Boca Raton, FL, pp 625-655

Huckins JN, Petty JD, Prest HF, Orazio CE, Clark RC (2000) Guide for the use of semipermeable membrane devices (SPMDs) as samplers of waterborne hydrophobic organic contaminants. Report for the American Petroleum Institute (API), API Publication 4690. API, Washington, DC

Huckins JN, Prest HF, Petty JD, Lebo JA, Hodgins MM, Clark RC, Alvarez DA, Gala WR, Steen A, Gale R, Ingersoll CG (2004) Overview and comparison of lipid-containing semipermeable membrane devices and oysters (Crassostrea gigas) for assessing organic chemical exposure. Environ Toxicol Chem 23:1617-1628

Huckins JN, Tubergen MW, Manuweera GK (1990) Semipermeable membrane devices containing model lipid: A new approach to monitoring the bioavailability of lipophilic contaminants and estimating their bioconcentration potential. Chemosphere 20:533-552 
Jimenez BD, Burtis LS (1989) Influence of environmental variables on the hepatic mixed-function oxidase system in bluegill sunfish, Lepomis machrochirus. Comp Biochem Physiol 93C:11-21

Kennedy SW, Lorenzen A, James CA, Collins BT (1993) Ethoxyresorufin $O$-deethylase and porphyrin analysis in chicken embryo hepatocyte cultures with a fluorescence multiwell plate reader. Anal Biochem 211:102-112

Kennedy SW, Lorenzen A, Norstrom RJ (1996) Chicken embryo hepatocyle bioassay for measuring cytochrome P450 1A-based 2,3,7,8-tetrachlorodibenzo- $p$-dioxin equivalent concentrations in environmental samples. Environ Sci Technol 30:706-715

Kočí V, Mlejnek M, Kochánková L (2003) Toxicological evaluation of exposed SPMD membranes. Cent Eur J Chem 1:28-34

Lebo JA, Zajicek JL, Huckins JN, Petty JD, Peterman PH (1992) Use of semipermeable membrane devices for in situ monitoring of polycyclic aromatic hydrocarbons in aquatic environments. Chemosphere 25:697-719

Li W, Wu WZ, Xu Y, Li L, Schramm KW, Kettrup A (2002) Measuring TCDD equivalents in environmental samples with the micro-EROD assay: Comparison with HRGC/HRMS data. Bull Environ Contam Toxicol 68:111-117

Ma TW, Wan XQ, Huang QH, Wang ZJ, Liu JK (2005) Biomarker responses and reproductive toxicity of the effluent from a Chinese large sewage treatment plant in Japanese medaka (Oryzias latipes). Chemosphere 59:281-288

Machala M, Matlova L, Svoboda I, Nezveda K (1996) Induction effects of polychlorinated biphenyls, polycyclic aromatic hydrocarbons and other widespread aromatic environmental pollutants on microsomal monooxygenase activities in chick embryl liver. Arch Toxicol 70:362-367

Moring JB, Rose DR (1997) Occurrence and concentrations of polycyclic aromatic hydrocarbons in semipermeable membrane devices and clams in three urban streams of the Dallas-Fort Worth metropolitan area, Texas. Chemosphere 34:551-566

Pacheco M, Santos MA (1999) Biochemical and genetic responses of adult eel (Anguilla anguilla L.) to resin acids and pulp mill effluent: Laboratory and field experiment. Ecotoxicol Environ Safety 42:81-93

Piskorska-Pliszczynska J, Keys B, Safe S, Newman MS (1986) The cytosolic receptor binding affinities and $\mathrm{AHH}$ induction potencies of 29 polynuclear aromatic hydrocarbons. Toxicol Lett 34:67-74

Qiao M, Chen YY, Zhang QH, Huang SB, Ma M, Wang CX, Wang ZJ (2006a) Identification of Ah receptor agonists in sediment of Meiliang Bay, Taihu Lake, China. Environ Sci Technol 40:14151419

Qiao M, Wang CX, Huang SB, Wang DH, Wang ZJ (2006b) Composition, sources, and potential toxicological significance of PAHs in the surface sediments of the Meiliang Bay, Taihu Lake, China. Environ Int 32:28-33

Rand GM, Wells PG, McCarty LS (1995) Introduction to aquatic toxicology. In: Rand GM, (ed) Fundamentals of aquatic toxicology: effects, environmental fate, and risk assessment. 2nd ed. Taylor \& Francis, Washington, DC, pp 3-67

Sanderson JT, Aarts JMMJG, Brouwer A, Froese KL, Denison MS, Giesy JP (1996) Comparison of Ah receptor-mediated luciferase and ethoxyresorufin $O$-deethylase induction in H4IIE cells: Implications for their use as bioanalytical tools for the detection of polyhalogenated aromatic hydrocarbons. Toxicol Appl Pharmacol 137:316-325

Schmitz H, Hagenmaier A, Hagenmaier H, Bock KW, Schrenk D (1995) Potency of mixtures of polychlorinated biphenyls as inducers of dioxin receptor-regulated CYP1A activity in rat hepatocytes and H4IIE cells. Toxicology 99:47-54

Schmitz H, Behnisch P, Hagenmaier A, Hagenmaier H, Bock KW, Schrenk D (1996) CYP1A1-inducing potency in H4IIE cells and chemical composition of technical mixtures of polychlorinated biphenyls. Environ Toxicol Pharmacol 1:73-79

Sverdrup LE, Nielsen T, Krogh PH (2002) Soil ecotoxicity of polycyclic aromatic hydrocarbons in relation to soil sorption, lipophilicity, and water solubility. Environ Sci Technol 36:24292435

Tillit DE, Giesy JP, Ankley GT (1991) Characterization of the rat hepatoma cell bioassay as a tool for assessing toxic potency of planar halogenated hydrocarbons in environmental samples. Environ Sci Technol 25:87-92

Van der Weiden ME, Hanegraaf FHM, Eggens ML, Celander M, Seinen W, Van den Berg M (1994) Temporal induction of cytochrome $\mathrm{P} 4501 \mathrm{~A}$ in the mirror carp (Cyprinus carprio) after administration of several polycyclic aromatic hydrocarbons. Environ Toxicol Chem 12:797-802

Verweij F, Booij K, Satumalay K, Van der Molen N, Van der Oost R (2004) Assessment of bioavailable PAH, PCB and OCP concentrations in water, using semipermeable membrane devices (SPMDs), sediments and caged carp. Chemosphere 54:1675-1689

Wang H, Wang CX, Wu WZ, Mo Z, Wang ZJ (2003) Persistent organic pollutants in water and surface sediments of Taihu Lake, China and risk assessment. Chemosphere 50:557-562

Whitlock JP (1990) Genetic and molecular aspects of 2,3,7,8-tetrachlorodibenzo- $p$-dioxin action. Annu Rev Pharmacol Toxicol 30:251-277

Willett KL, Gardinali PR, Sericano JL, Wade TL, Safe SH (1997) Characterization of the H4IIE rat hepatoma cell bioassay for evaluation of environmental samples containing polycuclear aromatic hydrocarbons (PAHs). Arch Environ Contam Toxicol 32:442-448

Wu WZ, Schwirzer SMG, Schramm KW, Wiebel FJ, Xu Y, Zhang YY, Yediler AKA (1996) Induction of ethoxyresorufin $O$-deethylase (EROD) as indicator of potentially harmful effects for dioxin-like compounds in environmental samples of Ya-Er Lake area, China. Fresenius Environ Bull 5:374-379

Wu WZ, Zhou BS, Xu Y, Schramm KW, Kettrup A (1999) Cytological and biochemical alterations in Carassius auratus hepatocytes from exposure to sediment contaning dioxins and related compounds. Arch Environ Contam Toxicol 37:358-363

Zacharewski T, Safe L, Safe S, Chittim B, DeVault D, Wiberg K, Bergqvist P, Rappe C (1989) Comparative analysis of polychlorinated dibenzo- $p$-dioxin and dibenzofuran congeners in Great Lakes fish extracts by gas chromatography-mass spectrometry and in vitro enzyme induction activities. Environ Sci Technol 23:730-735 